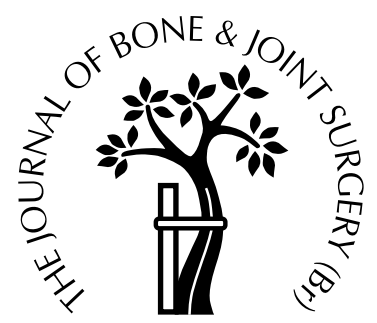

\title{
The results at ten years of the Insall-Burstein II total knee replacement
}

\section{CLINICAL, RADIOLOGICAL AND SURVIVORSHIP STUDIES}

\author{
P. L. S. Li, J. Zamora, G. Bentley \\ From the Royal National Orthopaedic Hospital, Stanmore, England
}

$\mathbf{W}$ e reviewed the outcome of 146 Insall-Burstein II total knee replacements carried out in 121 patients over a period of nearly four years in a general orthopaedic unit. At a mean follow-up of ten years, 94 knees in 78 patients were available for review. Six patients ( 7 knees) were lost to follow-up and 37 (45 knees) had died.

The clinical outcome using the scoring system of the Hospital for Special Surgery (HSS) was excellent or good in $79 \%$ of patients, fair in $14 \%$ and poor in $7 \%$. The mean preoperative HSS score was 31, improving to 79 at the latest review. Using the newer rating system of the Knee Society, the mean score at ten years was 87 and the mean functional score 56. The arc of flexion improved from a mean preoperative value of $88^{\circ}$ to $100^{\circ}$. The 18 patients who had had a previous high tibial osteotomy were analysed separately and were found to have benefited equally from the operation. Nine prostheses were revised, giving a cumulative survival rate of $92.3 \%$ at ten years. Radiological evaluation of 104 radiographs showed radiolucent lines around ten tibial components, none of which required revision. Anterior knee pain was a significant problem.

J Bone Joint Surg [Br] 1999;81-B:647-53.

Received 1 July 1998; Accepted after revision 11 February 1999

P. L. S. Li, MD, FRCS Orth, Consultant Orthopaedic Surgeon King's College Hospital, Denmark Hill, London SE5 9RS, UK.

J. Zamora, FRCS G, Registrar in Orthopaedics

Southend General Hospital, Prittlewell Chase, Westcliff-on-Sea, Essex SSO ORY, UK

G. Bentley, ChM, FRCS, Director

Institute of Orthopaedics, Royal National Orthopaedic Hospital Trust, Brockley Hill, Stanmore, Middlesex HA7 4LP, UK.

Correspondence should be sent to Mr P. L. S. Li at the Department of Orthopaedics, King's College Hospital, Denmark Hill, London SE5 9RS, UK.

(C)1999 British Editorial Society of Bone and Joint Surgery 0301-620X/99/49262\$2.00

VOL. 81-B, No. 4, JULY 1999
The Insall-Burstein Total Condylar knee prosthesis was first introduced in 1974 and heralded a successful era in knee replacement. ${ }^{1}$ Its evolution led to the development of a posterior-stabilised, cruciate-substituting prosthesis with an all-polyethylene tibial component which was introduced in $1978^{2}$ and modified further in 1980 , with the introduction of metal backing to improve load transmission at the boneimplant interface; the IB-II prosthesis (Zimmer, Swindon, UK; Fig. 1). ${ }^{3}$ Later developments included the introduction of modular components with stems and wedges to suit the needs of individual patients. To our knowledge, there are only two reports of the long-term results of this prosthesis, which has $25 \%$ of the market share in the UK. ${ }^{4}$ Both indicate that the clinical results are excellent when the operation is carried out by one of the original designers of the implant ${ }^{5}$ and that the long-term survivorship is of the

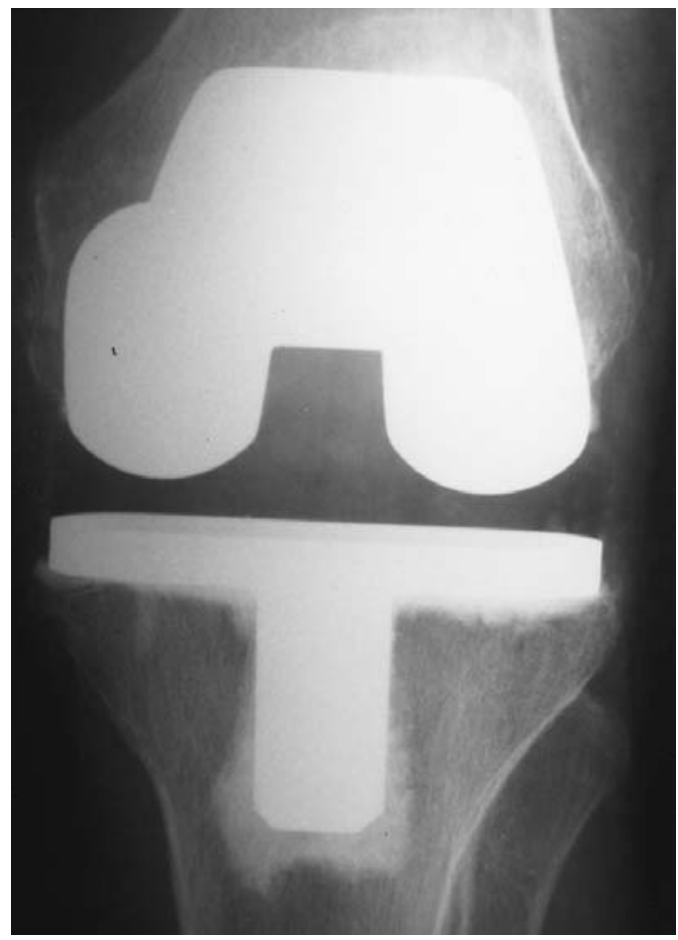

Fig. 1

The IB-II prosthesis, a posterior-stabilised, cruciate-substituting, condylar implant with a metal-backed tibial component. 
order of $98 \%{ }^{6}$ We present the ten-year results of the use of this prosthesis in a general orthopaedic unit.

\section{Patients and Methods}

Between May 1986 and March 1990, we carried out 146 total knee replacements (TKR) in 121 patients using the IBII prosthesis. There were 39 men and 82 women with a mean age of 68 years (46 to 86) at the time of operation. The diagnosis was osteoarthritis in 108 knees (6 posttraumatic), rheumatoid arthritis in 37 and pigmented villonodular synovitis in one. At a mean of ten years (8 to 12) after surgery, 78 patients (94 knees) were available for review. Of the remaining 43 patients, 37 (45 knees) had died, confirmed by the Office for National Statistics, and six (seven knees) had been lost to follow-up. The records of these 43 patients up to their last review were examined, giving a mean follow-up of 4.5 years (1 to 8 ).

Table I. The number of arthroplasties performed by each grade of surgeon

\begin{tabular}{lcl}
\hline Surgeon grade & Number & Percentage \\
\hline Professor & 20 & 13.6 \\
Consultant & 25 & 17.1 \\
Specialist registrar & 101 & 69.2 \\
\hline
\end{tabular}

The primary replacement was carried out by surgeons of varying experience (Table I). Specialist registrars-in-training were allowed to undertake supervised arthroplasties only after they had been taught the technique and were considered to be competent. The operation which was performed through a medial parapatellar approach, aimed to achieve correct limb alignment, good stability, normal patellar tracking and a good range of movement. Patellar resurfacing was carried out only in the presence of sufficient loss of articular cartilage and bone which might impair patellofemoral movement. Minor fibrillation or softening of the cartilage was not an indication to resurface the patella. A lateral release was carried out if there was tightness of the lateral retinaculum when tracking of the patella was tested at the end of the procedure. It was customary at that time to hold the patella reduced in the groove with one thumb during this test, but this is practised no longer. A combination of ampicillin and flucloxacillin was given to all patients, starting at the induction of anaesthesia and continuing into the postoperative period until the wound had healed. Anticoagulation with warfarin began 48 hours after the operation and continued until discharge from hospital, maintaining the INR at 1.5. Every knee was splinted in extension for 48 hours, but static quadriceps exercises were started without delay, with weight-bearing beginning at 24 hours, and flexion at 48 hours after removal of the splint. The mean length of hospital stay was 12 days (8 to 18 ).
Table II. The HSS scoring system for evaluation of clinical outcome

\begin{tabular}{|c|c|}
\hline & Point \\
\hline \multicolumn{2}{|l|}{ Pain } \\
\hline No pain at any time & 30 \\
\hline No pain on walking & 15 \\
\hline Mild pain on walking & 10 \\
\hline Moderate pain on walking & 5 \\
\hline Severe pain on walking & 0 \\
\hline No pain at rest & 15 \\
\hline Mild pain at rest & 10 \\
\hline Moderate pain at rest & 5 \\
\hline Severe pain at rest & 0 \\
\hline \multicolumn{2}{|l|}{ Function (22 points) } \\
\hline Walking and standing unlimited & 12 \\
\hline $\begin{array}{l}\text { Walking distance of } 5 \text { to } 10 \text { blocks } \\
\text { and standing ability intermittent ( }<30 \text { minutes) }\end{array}$ & 10 \\
\hline Walking 1 to 5 blocks and standing & \\
\hline ability up to 30 minutes & 8 \\
\hline Walking less than 1 block & 4 \\
\hline Cannot walk & 0 \\
\hline Climbing stairs & 5 \\
\hline Climbing stairs with support & 2 \\
\hline Transfer activity & 5 \\
\hline Transfer activity with support & 2 \\
\hline \multicolumn{2}{|l|}{ Range of movement (22 points) } \\
\hline $\begin{array}{l}1 \text { point for each } 8^{\circ} \text { of arc motion } \\
\text { to a maximum of } 18 \text { points }\end{array}$ & 18 \\
\hline \multicolumn{2}{|l|}{ Muscle strength (10 points) } \\
\hline Excellent: cannot break the quadriceps power & 10 \\
\hline Good: can break the quadriceps power & 8 \\
\hline Fair: moves through the arc of motion & 4 \\
\hline Poor: cannot move through the arc of motion & 0 \\
\hline \multicolumn{2}{|l|}{ Fixed deformity (10 points) } \\
\hline No deformity & 10 \\
\hline Less than $5^{\circ}$ & 8 \\
\hline $5^{\circ}$ to $10^{\circ}$ & 5 \\
\hline More than $10^{\circ}$ & 0 \\
\hline \multicolumn{2}{|l|}{ Instability } \\
\hline None & 10 \\
\hline Mild: 0 to $5^{\circ}$ & 8 \\
\hline Moderate: $5^{\circ}$ to $15^{\circ}$ & 5 \\
\hline Severe: more than $15^{\circ}$ & 0 \\
\hline \multicolumn{2}{|l|}{ Subtraction } \\
\hline One cane & 1 \\
\hline One crutch & 2 \\
\hline Two crutches & 3 \\
\hline Extension lag of $5^{\circ}$ & 2 \\
\hline Extension lag of $10^{\circ}$ & 3 \\
\hline Extension lag of $15^{\circ}$ & 5 \\
\hline Each $5^{\circ}$ of varus & 1 \\
\hline Each $5^{\circ}$ of valgus & 1 \\
\hline
\end{tabular}

All knees were evaluated before operation using the Hospital for Special Surgery (HSS) scoring system ${ }^{7}$ (Table II) in which a score of 85 to 100 points was excellent, 70 to 84 good, 60 to 69 fair and less than 60 poor. In accordance with recent studies ${ }^{5}$ assessment after operation was determined using the newer Knee Society rating system ${ }^{8}$ (Table III), in addition to the HSS score. In this way, we aimed to compare results across centres directly.

The 78 patients available for review at ten years were all assessed clinically in the outpatient department. Survival analysis, using revision as endpoint, was determined by the method of Armitage and Berry. ${ }^{9}$ A survival curve was plotted, showing the best- and worst-case scenarios. 


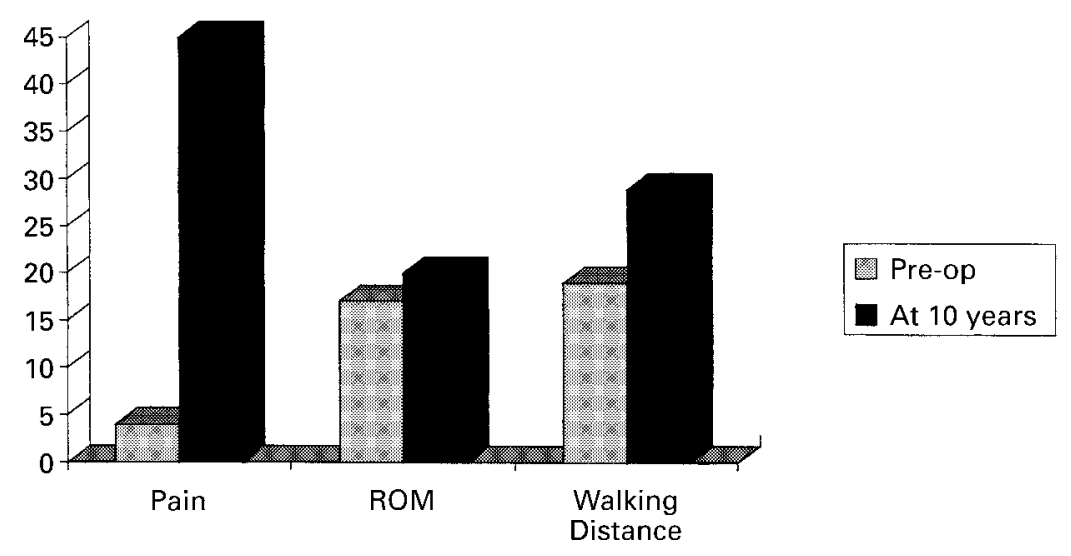

Fig. 2

Pain, range of movement (ROM) and walking distance, assessed according to the Knee Society ratings, for the 87 intact arthroplasties before operation and at follow-up at ten years.

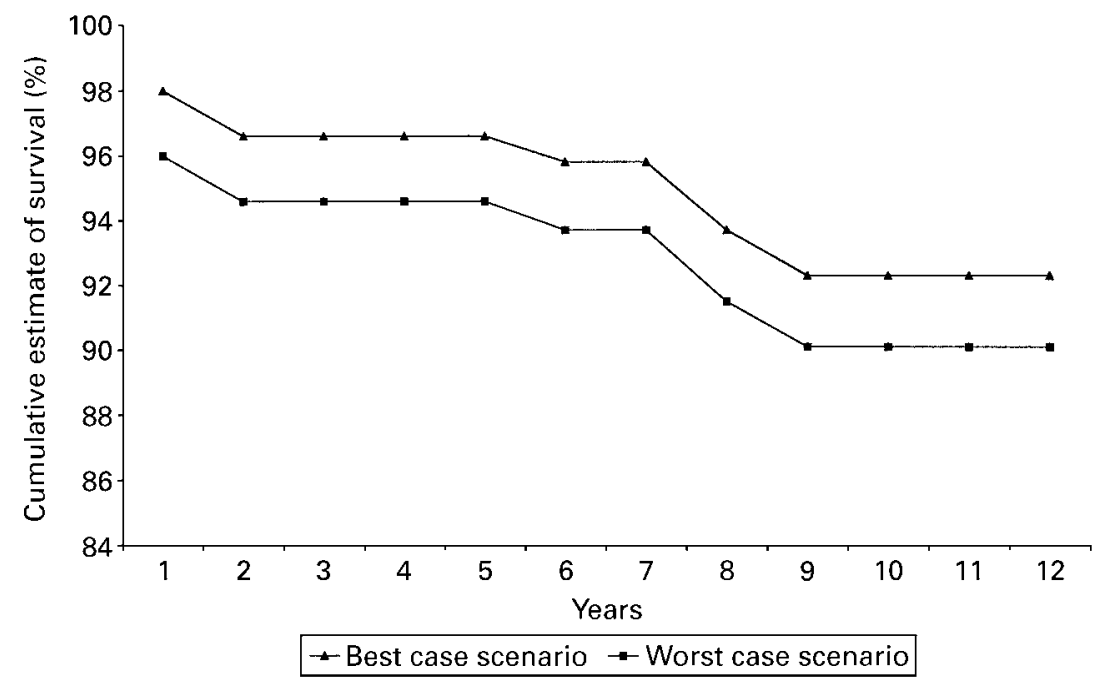

Fig. 3

The survival curve showing the best- and worstcase scenarios.

Radiographs were assessed according to the method described by the Knee Society. ${ }^{10}$ We analysed short anteroposterior (AP) views and lateral projections taken in $20^{\circ}$ of flexion, with both radiographs taken standing to determine the overall tibiofemoral alignment, the position of the components with respect to their individual bone, and also for the presence and extent of radiolucent lines.

\section{$\underline{\text { Results }}$}

Clinical. Seven revision operations were carried out in six patients (1 bilateral), leaving 87 intact arthroplasties for analysis. The mean preoperative HSS score was 31 points (10 to 57), and at the latest review it was 79 (30 to 98). A total of 69 knees $(79 \%)$ was rated excellent or good, 12 $(14 \%)$ as fair and six $(7 \%)$ as poor. The 87 knees were also assessed according to the newer rating system of the Knee Society and at ten years the mean score was 87 (25 to 100) while the mean functional score was 56 (0 to 100). The poor functional score reflected the increasing age and infirmity of this group of patients. Pain, range of movement and walking distance were also assessed separately (Fig. 2).

The average pain score before operation on the Knee Society rating was 4 , equivalent to continual moderate to severe pain, which improved to 45 , equivalent to occasional mild pain, after TKR. Ten years after arthroplasty $79 \%$ of patients reported no pain, in $13 \%$ it was mild and in $7 \%$ moderate. Only one patient had severe pain which was not related to her arthroplasty.

The mean preoperative range of movement was $88^{\circ}(10$ to 120 ) and this improved to $100^{\circ}$ (30 to 130) ten years after the primary replacement. A functionally acceptable range of movement of more than $90^{\circ}$ was achieved in $85 \%$ of patients. At a mean of ten years after replacement, five of the surviving 87 knees had a range of flexion of less than $60^{\circ}$. Of these five patients, two with primary osteoarthritis and three with post-traumatic arthritis, four had had less than $60^{\circ}$ of flexion before operation.

The mean walking distance before operation was less than five blocks (500 metres) on the Knee Society rating. Ten years after the arthroplasty, this had improved to between 500 and 1000 metres, despite the patients' increasing age and frailty. One-third of patients could walk over 1000 metres (Table IV).

The mean HSS score for the 43 patients ( 52 knees) who died or were lost to follow-up, obtained from their last review, was 70 (37 to 92). There were two revisions in this group giving a total of nine for the whole series. The 
Table III. The Knee Society rating system for evaluation of clinical outcome*

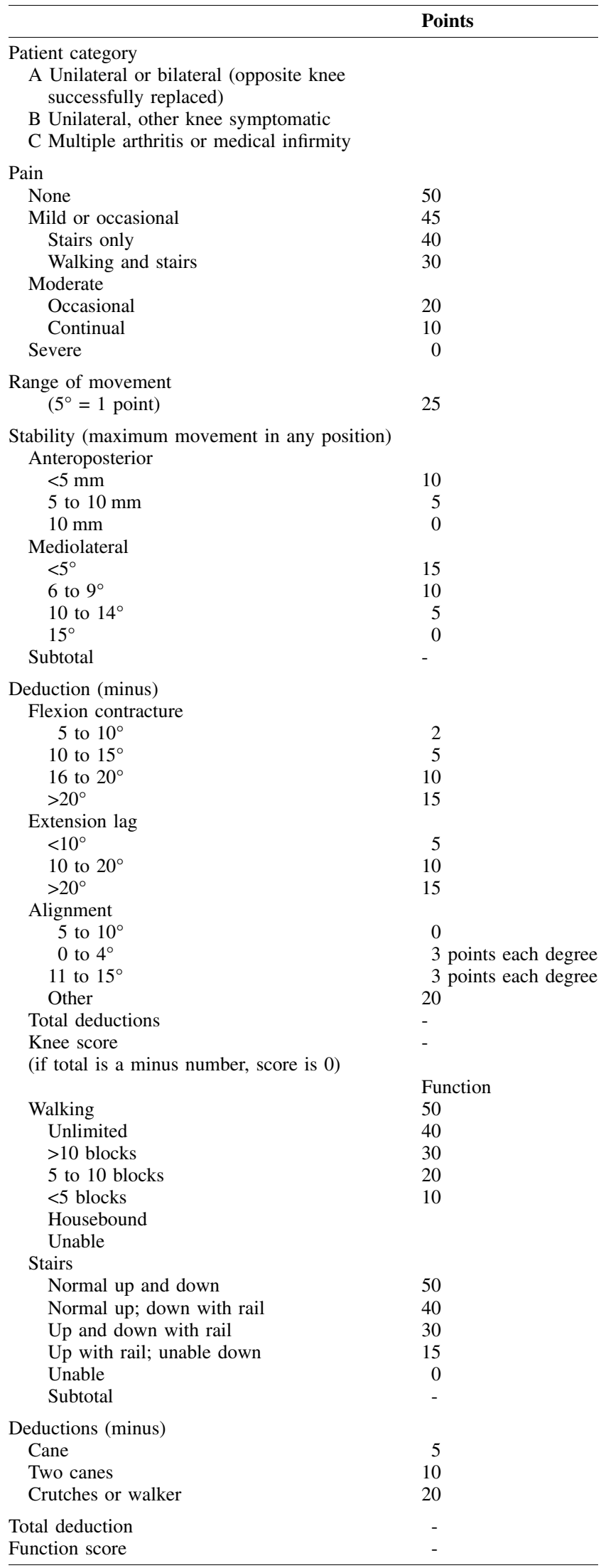

Table IV. Clinical details showing the mean results before operation and at ten years

\begin{tabular}{lcc}
\hline & Preoperative & At 10 years \\
\hline HSS score & 31 & 79 \\
Knee score & - & 87 \\
Functional score & - & 56 \\
Pain* & 4 & 45 \\
Flexion arc (degrees) & 88 & 100 \\
Walking distance $(\mathrm{m})$ & $<500$ & 500 to 1000 \\
Cumulative survival rate $(\%)$ & - & 92.3
\end{tabular}

* points on the Knee Society rating system

revision rate for consultants was 4.4\% (2 of 45) and for specialist registrars $6.9 \%$ (7 of 101).

The data for 18 patients who had had a previous high tibial osteotomy before total knee replacement (TKR) were analysed separately. Their mean preoperative HSS score was 37 (12 to 49), which improved to 80 (41 to 94) at the last review. Their pain score on the Knee Society rating improved from a mean of 3 points to 47 ; their mean range of movement improved from $88^{\circ}$ to $98^{\circ}$, and their mean walking distance from less than 500 metres to between 500 and 1000 metres. These figures are similar to the results seen in the whole series.

One of the most troublesome symptoms after TKR is persistent anterior knee pain. In this series, the decision to resurface the patella was made by the operating surgeon on the basis of significant loss of cartilage and bone as seen at operation. Thus, 82 patellae were resurfaced and 64 were not. Of the 64 patients who appeared to have normal or nearly normal patellofemoral joints, eight required secondary resurfacing for troublesome anterior knee pain on activities such as climbing. The initial diagnosis was osteoarthritis in five, rheumatoid arthritis in two and post-traumatic osteoarthritis in one. At the ten-year review, of nine surviving rheumatoid patients who did not have their patellae resurfaced primarily, only one had troublesome anterior knee pain which improved, but was not abolished, by later resurfacing.

Survival analysis. Table V is the table from which we have drawn the survival curve (Fig. 3) and demonstrates the best- and worst-case scenarios. There were nine revisions, giving a cumulative survival rate of $92.3 \%$ at ten years. If all the seven knees lost to follow-up are assumed to have failed, the cumulative survival at ten years is $88.6 \%$.

Nine revisions were carried out, five for infection and four for aseptic loosening. Staphylococcus aureus was involved in two of the infected patients and Enterobacter in one. No organisms were isolated from the other two. Four of the infected knees were successfully treated, two by staged reimplantation and two by arthrodesis. One knee remains infected despite excision of the components and the insertion of an antibiotic-laden cement spacer. The remaining revisions were undertaken for aseptic loosening of the tibial components at $6,8,8$ and 9 years from the initial arthroplasty. Two were carried out in a single patient with possible neuropathic joints who had little pain but in whom radiographs showed advanced disorganisation of 


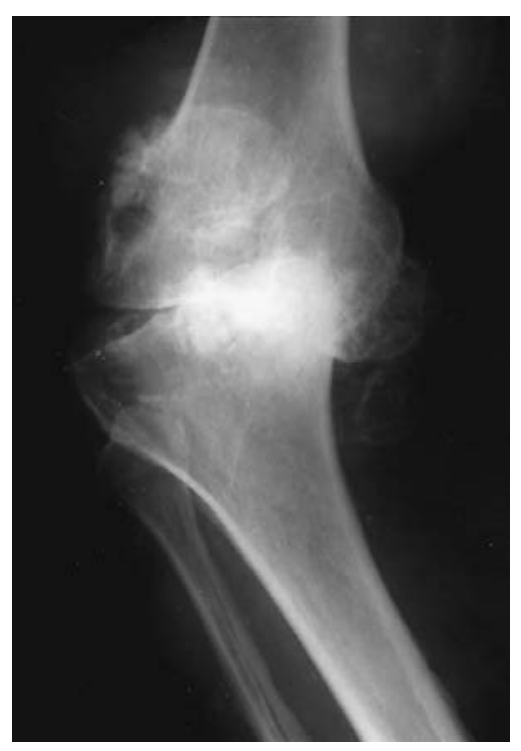

Fig. 4a

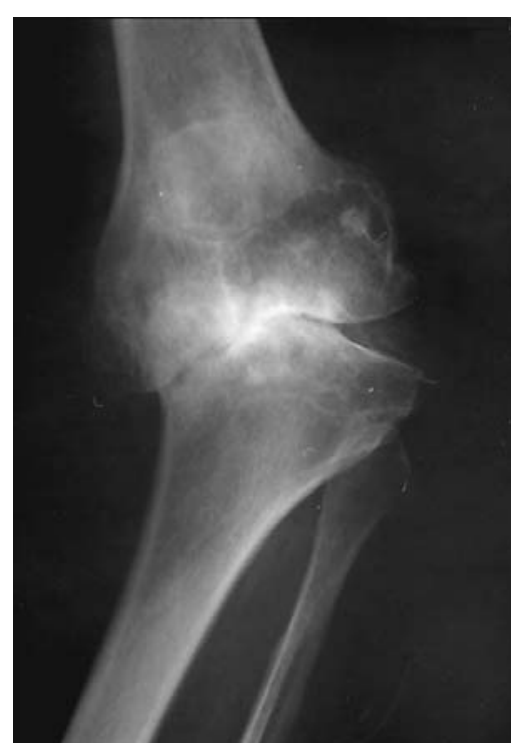

Fig. 4b
Radiograph showing the knees of a woman who developed recurrence of deformity and loosening of the tibial component in each knee, six and eight years after primary bilateral TKR

Table V. Survival table for the 146 total knee replacements

\begin{tabular}{|c|c|c|c|c|c|c|c|c|c|c|}
\hline Year & $\begin{array}{l}\text { Number of } \\
\text { knees at } \\
\text { start }\end{array}$ & Success & Lost & Died & Failed & $\begin{array}{l}\text { Number at } \\
\text { risk }\end{array}$ & $\begin{array}{l}\text { Proportion } \\
\text { failing } \\
(\%)\end{array}$ & $\begin{array}{l}\text { Proportion } \\
\text { succeeding } \\
(\%)\end{array}$ & $\begin{array}{l}\text { Cumulative } \\
\text { estimate of } \\
\text { survival } \\
(\%)\end{array}$ & $\begin{array}{l}95 \% \\
\text { confidence } \\
\text { intervals }\end{array}$ \\
\hline 0 to 1 & 146 & 0 & 0 & 3 & 3 & 144.5 & 2.0 & 98.0 & 98.0 & 2.3 \\
\hline 1 to 2 & 140 & 0 & 0 & 1 & 2 & 139.5 & 1.4 & 98.6 & 96.6 & 3.1 \\
\hline 2 to 3 & 137 & 0 & 0 & 7 & 0 & 133.5 & 0.0 & 100.0 & 96.6 & 3.1 \\
\hline 3 to 4 & 130 & 0 & 2 & 7 & 0 & 125.5 & 0.0 & 100.0 & 96.6 & 3.1 \\
\hline 4 to 5 & 121 & 0 & 2 & 6 & 0 & 117 & 0.0 & 100.0 & 96.6 & 3.3 \\
\hline 5 to 6 & 113 & 0 & 2 & 12 & 1 & 106 & 0.9 & 99.1 & 95.8 & 3.7 \\
\hline 6 to 7 & 98 & 0 & 1 & 3 & 0 & 96 & 0.0 & 100.0 & 95.8 & 4.0 \\
\hline 7 to 8 & 94 & 5 & 0 & 3 & 2 & 90 & 2.2 & 97.8 & 93.7 & 5.0 \\
\hline 8 to 9 & 84 & 22 & 0 & 3 & 1 & 71.5 & 1.4 & 98.6 & 92.3 & 5.8 \\
\hline 9 to 10 & 58 & 31 & 0 & 0 & 0 & 42.5 & 0.0 & 100.0 & 92.3 & 7.0 \\
\hline 10 to 11 & 27 & 16 & 0 & 0 & 0 & 19.0 & 0.0 & 100.0 & 92.3 & 10.3 \\
\hline 11 to 12 & 11 & 11 & 0 & 0 & 0 & 5.5 & 0.0 & 100.0 & 92.3 & 16.1 \\
\hline
\end{tabular}

both knees (Fig. 4). She developed recurrence of the deformity and loosening of the tibial component in each knee, six and eight years after the initial operation.

Complications other than revisions. Eight patients had anterior knee pain of such severity as to warrant secondary patellar resurfacing. Six improved but in two the HSS score remained poor. There was patellar maltracking in three knees requiring lateral release and one patient had a ruptured patellar tendon which was successfully repaired.

Seven patients required manipulation under anaesthesia to improve their range of movement. Six had a postoperative wound discharge, one of whom later developed a periprosthetic infection. There was one case of non-fatal pulmonary embolus and four of deep-vein thrombosis. One patient had a cerebrovascular accident from which she recovered fully and another a fracture of the posterolateral cortex of the tibia.

Radiological analysis. The radiographs of 104 knees were analysed according to the method of the Knee Society. ${ }^{10}$
The mean tibiofemoral angle was $5.6^{\circ}$ of valgus (10 varus to 12 valgus). The mean valgus position of the femoral component on the AP radiographs was $96.5^{\circ}$ (90 to 112) and the mean flexion was $3^{\circ}$ on the lateral radiographs $\left(5^{\circ}\right.$ extension to $20^{\circ}$ flexion). Only two components were placed in extension. The varus-valgus position of the tibial component was measured on the AP radiographs as the angle formed by the tibial plateau and the long axis of the tibia on the medial side. The mean position of the tibial component was $89^{\circ}$, that is slightly varus (84 to 98 ). The mean position of the tibial component on the lateral radiographs was $88^{\circ}$ (84 to 98 ), that is slight flexion. There was significant radiolucency (a score of 5 or more) around ten tibial components but in none of the femoral implants. None of these knees has required revision. Function was excellent or good in eight knees, fair in one and poor in one. The latter patient had little pain, despite severe varus deformity, and did not wish to have a revision arthroplasty. 
We did not measure the wear of the polyethylene components. Gross wear ${ }^{11}$ did not appear to be a problem in our patients.

\section{Discussion}

Our aim was to present data from a general orthopaedic unit on the long-term outcome of one of the most widely used knee prostheses. It cannot be assumed that the outcome of TKR in a general orthopaedic unit will be comparable to the results obtained in an international specialist centre where the operating surgeon is highly experienced and extremely familiar with his implant. ${ }^{5,6}$ Our unit in Stanmore represents a common situation in the UK where the operation is usually carried out by different consultants or by trainees under their supervision. The IB-II had just been introduced during the period of this study and the results would inevitably reflect the effect of the associated learning curve.

At ten years, only $79 \%$ of our knees were rated excellent or good, compared with $96 \%$ in the unit of the originator, but our patients started with a lower mean preoperative HSS score of 31 points which subsequently improved to 79 points. In the series of Colizza et $\mathrm{al}^{5}$ the mean preoperative HSS score was 51 points, improving to 85 points after comparable follow-up. This difference may reflect variations in the criteria for selection of patients for total knee replacement in the two centres and the lower initial scores of our patients indicate that they were more severely disabled. On the rating system of the Knee Society, our mean knee score at ten years was 87 points compared with 92 points for the series of Colizza et al, ${ }^{5}$ while the corresponding mean functional scores were 56 and 71, reflecting the increasing age and frailty of our patients.

One of the claimed advantages of cruciate substitution is an improved range of movement compared with designs which retain the posterior cruciate ligament. In our series, flexion improved from a mean of $88^{\circ}$ preoperatively to $100^{\circ}$ at ten years. In the originator's series, the improvement was from $94^{\circ}$ to $110^{\circ}$. Most patients who had a poor final range of movement started off with a similar deficiency, often due to post-traumatic osteoarthritis.

The outome of TKR after high tibial osteotomy is controversial. Initial reports suggested that the clinical outcome was not as good as after primary TKR, ${ }^{12}$ but more recent publications have been encouraging. ${ }^{13-15}$ In our patients, the results of TKR after high tibial osteotomy appeared to be as good as after primary TKR, but a larger number of patients would be required to resolve the issue.

Nine prostheses were revised in our series, giving a cumulative rate of survival of $92 \%$ at ten years, compared with $96 \%$ after 11 years for the originator. Five of the revisions were for infection giving a rate of periprosthetic sepsis of $3.4 \%$ despite the use of a downflow laminar ventilation system and prophylactic administration of antibiotics. Body-exhaust suits were not used. The most likely explanation for the high rate of infection is resistance of the organisms to the antibiotics prescribed. In one case, methicillin-resistant Staphylococcus aureus was isolated, in another penicillin-resistant Enterobacter. The remaining four revisions were for aseptic loosening of the tibial components, two occurring in neuropathic joints.

A total of 15 patients had a lateral release at the original operation, after which two had moderate to severe anterior knee pain. Both had not had their patellae resurfaced and after secondary resurfacing one remains symptomatic. Three knees required a subsequent lateral release. It is possible that this could have been due to the practice of holding the patella reduced in the articular groove with one thumb during testing for patellar tracking before wound closure. We now test tracking without supporting the patella. Lateral release is carried out if there is a tendency to lateral subluxation. The patients in our series with rheumatoid arthritis were not especially at risk of developing troublesome anterior knee pain in the absence of resurfacing provided that the patellofemoral compartment was well preserved.

Most of the radiographs were satisfactory with regard to tibiofemoral alignment and the position of the individual components. Significant radiolucency correlated poorly with clinical function (Fig. 5). Ten tibial components had significant lucent lines at the cement-bone interface, but function was poor in only one patient who declined revision since he had no pain. The poor correlation between radiographs and function has been previously noted. ${ }^{16,17}$

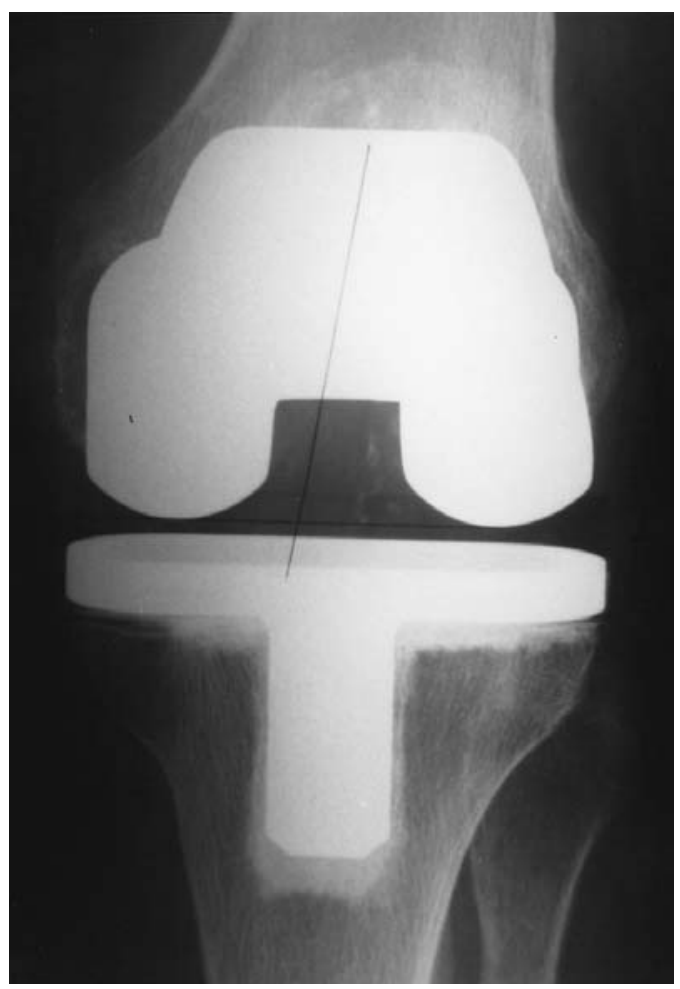

Fig. 5

Radiograph showing satisfactory tibiofemoral alignment; radiolucency correlated poorly with clinical function. 
We have presented the long-term clinical, radiological and survival results of one of the most widely used knee prostheses, the Insall-Burstein II, a modified total condylar implant with cruciate substitution. Whether the operation is carried out in a general orthopaedic unit by consultants or trainees of adequate experience does not influence the outcome.

No benefits in any form have been received or will be received from a commercial party related directly or indirectly to the subject of this article.

\section{References}

1. Insall J, Scott WN, Ranawat CS. The total condylar prosthesis: a report of two hundred and twenty cases. J Bone Joint Surg [Am] 1979;61-A:173-80.

2. Insall JN, Lachiewicz PF, Burstein AH. The posterior stabilized condylar prosthesis: a modification of the total condylar design: two to four-year clinical experience. J Bone Joint Surg [Am] 1982; 64-A:1317-23.

3. Bartel DL, Burstein AH, Santavicca EA, Insall JN. Performance of the tibial component in total knee replacement: conventional and revision designs. J Bone Joint Surg [Am] 1982;64-A:1026-33.

4. Liow RYL, Murray DW. Which primary total knee replacement: a review of currently available TKR in the United Kingdom. Ann R Coll Surg Engl 1997;79:335-40.

5. Colizza WA, Insall JN, Scuderi JR. The posterior stabilized total knee prosthesis: assessment of polyethylene damage and osteolysis after a ten-year-minimum follow-up. J Bone Joint Surg [Am] 1995; 77-A: $1713-20$
6. Font-Rodriguez DE, Scuderi GR, Insall N. Survivorship of cemented total knee arthroplasty. Clin Orthop 1997;345:79-86.

7. Insall JN, Ranawat CS, Aglietti P, Shine J. A comparison of four models of total knee-replacement prostheses. J Bone Joint Surg [Am] 1976;58-A:754-65.

8. Insall JN, Dorr LD, Scott RD, Scott WN. Rationale of the Knee Society clinical rating system. Clin Orthop 1989;248:13-4.

9. Armitage P, Berry G. Statistical methods in medical research. Second ed. Oxford: Blackwell Scientific, 1987.

10. Ewald FC. The knee society total knee arthroplasty roentgenographic evaluation and scoring system. Clin Orthop 1989;248:9-12.

11. Engh GA, Dwyer KA, Hanes CK. Polyethylene wear of metalbacked tibial components in total and unicompartmental knee prostheses. J Bone Joint Surg [Br] 1992;74-B:9-17.

12. Windsor RE, Insall JN, Vince KG. Technical considerations of total knee arthroplasty after proximal tibial osteotomy. J Bone Joint Surg [Am] 1988;70-A:547-55.

13. Bergenudd H, Sahlstrom A, Sanzen L. Total knee arthroplasty after failed proximal tibial valgus osteotomy. J Arth roplasty 1997; 12:635-8.

14. Takai S, Yoshino N, Hirasawa Y. Revision total knee arthroplasty after failed high tibial osteotomy. Bull Hosp Jt Dis 1997;56:245-50.

15. Surace FM, McNab ISH, Bentley G. "The PCL. To sacrifice or to preserve?": prospective comparison of the kinemax and press-fit condylar total knee systems. J Bone Joint Surg [Br] 1997;79-B Suppl 2:268.

16. Ritter MA, Gioe TJ, Stringer EA. Radiolucency surrounding the posterior cruciate condylar total knee prosthetic components. Clin Orthop 1981;160:149-52.

17. Ecker ML, Lotke PA, Windsor RE, Cella JP. Long-term results after total condylar knee arthroplasty: significance of radiolucent lines. Clin Orthop 1987;216:151-8. 